\title{
Position Control of Switched Reluctance Motor Using Super Twisting Algorithm
}

\author{
Muhammad Rafiq Mufti, ${ }^{1}$ Qarab Raza Butt, ${ }^{2}$ S. Iqbal, ${ }^{3}$ and M. Ramzan ${ }^{4}$ \\ ${ }^{1}$ Department of Computer Sciences, COMSATS Institute of Information Technology, Vehari, Pakistan \\ ${ }^{2}$ Centre for Advanced Studies in Engineering (CASE), Islamabad, Pakistan \\ ${ }^{3}$ Department Informatics \& Systems, School of Systems and Technology, University of Management and Technology, Lahore, Pakistan \\ ${ }^{4}$ Department of Mathematics, The Islamia University of Bahawalpur, Pakistan
}

Correspondence should be addressed to Muhammad Rafiq Mufti; rafiq_mufti@ciitvehari.edu.pk

Received 21 September 2015; Revised 5 December 2015; Accepted 8 December 2015

Academic Editor: Bin Jiang

Copyright (C) 2016 Muhammad Rafiq Mufti et al. This is an open access article distributed under the Creative Commons Attribution License, which permits unrestricted use, distribution, and reproduction in any medium, provided the original work is properly cited.

\begin{abstract}
The inherent problem of chattering in traditional sliding mode control is harmful for practical application of control system. This paper pays a considerable attention to a chattering-free control method, that is, higher-order sliding mode (super twisting algorithm). The design of a position controller for switched reluctance motor is presented and its stability is assured using Lyapunov stability theorem. In order to highlight the advantages of higher-order sliding mode controller (HOSMC), a classical first-order sliding mode controller (FOSMC) is also applied to the same system and compared. The simulation results reflect the effectiveness of the proposed technique.
\end{abstract}

\section{Introduction}

Switched reluctance (SR) motor has never been gaining much interest in high precision and high speed motion actuators because of its difficult control structure and high force ripples. Moreover, it is highly dependent on its magnetic structure and time varying parameters and, therefore, it is difficult to model, simulate, and control. A number of control techniques have been proposed in order to control SR motor but little work has been done on position control applications. In the recent years, SR motor has been gaining much popularity in industrial and research laboratory applications such as material transfer, packaging, and electrical wiring, because of advancement in power electronics, digital signal processing, and advanced control strategies for nonlinear systems $[1,2]$. A PID controller was proposed in [3] for position control problem. The proposed method could be applied in putting rotor in any intermediate position but their work did not compensate the large position error. In [4], state feedback technique was introduced for the same problem of SR motor by incorporating rotor position and phase current. However, the proposed technique needs the complete knowledge of the system dynamics. In [5], a scheme for motion control purpose using SR motor was suggested for high performance servo drive applications. The scheme was implemented using TMS320F2812 DSP card and comprised PD controller for position and PI controller for speed control, and satisfactory results were reported. In [6], a position controller for linear SR motor was developed for automation process. The proposed scheme used the novel lookup table representing current-force-position to achieve force linearization. Then by employing loop shaping design, a compensator was developed to enhance the system performance. The same work was performed by [7] using dSPACE platform. However, their work did not consider the magnetic saturation of the motor. It is important to note that, for high output power, the motor should be operated in magnetic saturation because rotor position is proportional to magnetic saturation. The magnetization curve depending upon the rotor position is an important factor in modelling of SR motor for performance 
analysis and advanced control purposes. A number of methods have been proposed to measure motor characteristics. In [8], a method based on static torque was presented to measure flux-linkage profile of SR motor. Because of torque offset caused by asymmetry of mechanical elements, this method is not acceptable for machines with small torque values. In [9], the magnetic characteristics were measured by digital signal processor based method, in which the accuracy is verified by coenergy method and finite element method.

Sliding mode technique has been successfully applied for motor control problems for a couple of decades due to its simplicity, robustness, and insensitivity to certain system parameter variations $[10,11]$. In [12], work on AC servo motor was carried out and a controller based on this technique was developed for position control application. The designed controller did not demand the prior knowledge of the disturbance and its performance was evaluated by comparing with the conventional schemes. In [13], permanent magnet stepper motor was studied and investigated for position regulation problem. The designed scheme is comprised of observer based sliding mode controller that utilized the estimated rotor position and load torque. The simulation results proved the effectiveness of the designed scheme. In [14], a sliding mode controller for position tracking problem was presented for permanent magnet DC motor. The proposed scheme utilized two different approaches. The first approach was taken from Slotine and the other from Utkin. The performance of the controller was tested on variable inertia and torque load. After comparison with classical approach of PI controller, it was shown that the designed controller was robust in case of parameter variations and unknown disturbances. In [15], this technique was adopted and applied on position control of brushless servo motor. Robustness and fast dynamic response were also reported.

The sliding mode technique has two major drawbacks. It is not robust in the reaching phase before coming to the sliding surface and exhibits chattering on reaching the sliding surface [16]. Chattering is undesirable in electrical systems because it causes unmodelled dynamics to excite which can make the system unstable. Several methods have been presented in the literature to reduce chattering. One of the proposed methods was to introduce boundary layer near the sliding surface [17]. This caused the delay in reversal of direction of the representative point. However, this method could not be applied to all types of motors. Moreover, using this method, steady state error might exist. Some authors (e.g., [18]) used adaptive sliding mode control (ASMC) approach for chattering reduction. However, this technique was still sensitive to parameter variations and unknown disturbances. There was a need of such a control scheme that catered for both the problems of conventional sliding mode. The use of sliding mode was also reported in $[19,20]$ for position control application of induction motor and synchronous motor. This scheme was further modified in [21] by adding fuzzy logic control with sliding mode. The designed scheme contained the integrator to eliminate the steady state error and proved to be good for position tracking application. In [22], sliding mode was combined with PID and fuzzy logic technique to overcome chattering issue and applied this scheme on
TABLE 1: Parameters of switched reluctance motor.

\begin{tabular}{lc}
\hline Parameter & Value \\
\hline Number of phases & 3 \\
Number of stator poles & 6 \\
Number of rotor poles & 8 \\
Inertia $(J)$ & $0.1 \mathrm{~N} \cdot \mathrm{ms}^{2}$ \\
Coefficient of friction $(B)$ & $0.1 \mathrm{~N} \cdot \mathrm{ms}$ \\
Phase resistance & $4.7 \Omega$ \\
DC voltage supply & $250 \mathrm{v}$ \\
\hline
\end{tabular}

position control of DC motor. The simulation results reveal that chattering problem is considerably reduced. Chen and Hsu [23] enhanced the sliding mode with fuzzy logic control to overcome chattering issue and then controller was applied on position control of induction motor. It is shown that the designed controller behaved well in chattering reduction, and fast dynamic response is also achieved. Fallahi and Azadi [24] added fuzzy and traditional PID control with sliding mode control for chattering reduction. The proposed controller was further employed for position control of DC motor. A fuzzy logic control with sliding mode was also reported in [25] for position control purpose. The designed technique was employed on DC motor. It is observed that chattering issue is considerably reduced. However, drawback of fuzzy logic technique is the dependency of equivalent control and system parameters.

One of the possible solutions of chattering reduction was the use of higher-order sliding mode (HOSM) control [16]. HOSM had been used for a number of engineering applications [26-29]. In [30], HOSM controller was proposed for position control problem of induction motor using super twist algorithm. Its performance was tested at high inertia and DC motor loads and compared with conventional controllers. The evaluation results show that the proposed scheme significantly outperforms the other ones. A good comparison of PI and sliding mode control was given in [31] for SR motor. To compensate chattering and for fast dynamic response, a robust controller based on super twisting algorithm for speed regulation and tracking problem was suggested. The simulation results indicate that the proposed controller outperforms the PI and sliding mode.

In this paper, we propose position controller based on super twisting algorithm for SR motor. The rest of the paper is organized as follows. Section 2 contains mathematical model of the system. Section 3 deals with controllers structures where FOSMC and SOSMC are designed. Section 4 presents and discusses the important simulation results and finally, in Section 5, some concluding remarks are established.

\section{Mathematical Model of SR Motor}

The mathematical model used in this work is that of a 3-phase SR motor whose parameters are given in Table 1. The dynamic 
system consists of electrical and mechanical subsystems [31] which are given in state space form as below:

$$
\begin{aligned}
& \frac{d \theta}{d t}=\omega, \\
& \frac{d \omega}{d t}=\frac{1}{J}\left(T_{e}-B \omega-T_{L}\right), \\
& \frac{d i_{j}}{d t}=\left(\frac{\partial \lambda_{j}\left(\theta, i_{j}\right)}{\partial i_{j}}\right)^{-1}\left(u_{j}-R i_{j}-\omega \frac{\partial \lambda_{j}\left(\theta, i_{j}\right)}{\partial \theta}\right), \\
& \text { where } j=1,2,3,
\end{aligned}
$$

and $\theta$ is rotor position, $u_{j}$ is voltages of $j$ th phase, $R_{j}$ is resistance to the $j$ th phase, $i_{j}$ is current in the $j$ th phase, $\lambda_{j}$ is flux linkages in $j$ th phase, $\omega$ is angular velocity of rotor, $T_{e}$ is total electromagnetic torque, $T_{L}$ is load torque, $J$ is moment of inertia (rotor), and $B$ is coefficient of friction.

\section{Controllers Designs}

For SR motor operation, a commutation scheme is necessary, which plays an important role in motor efficiency and performance. A new commutation scheme has been proposed in previous work of author(s) in [32], which optimizes the power consumption by energizing at the most two out of three phases at any instant.

3.1. First-Order Sliding Mode Controller (FOSMC) Design. FOSMC design can be accomplished in two steps. In first step, the switching surface depending upon the error dynamics is designed and in the second step, the control law is formulated in such a way that it would guarantee to take the system states to the sliding manifold. The main feature of this technique is to keep the system insensitive to certain parameter variations and unknown disturbances, once the system is in sliding manifold [33]. The switching surface is chosen keeping in view the Slotine approach [33] as

$$
s=\left(\frac{d}{d t}+D\right)^{n-1} e,
$$

where $D$ is positive constant and $e(t)=\theta(t)-\theta_{\text {ref }}(t) . \theta_{\text {ref }}(t)$ is the desired position and $n$ is the order of the system. Since $n=3$, therefore

$$
\begin{aligned}
& s=\left(\frac{d}{d t}+D\right)^{2} e, \\
& s=\frac{d^{2}}{d t^{2}} e+2 D \frac{d}{d t} e+D^{2} e .
\end{aligned}
$$

For simplicity, $2 D=D_{1}$ and $D^{2}=D_{2}$ and then (6) can be written as

$$
s=\ddot{e}+D_{1} \dot{e}+D_{2} e,
$$

where $D_{1}$ and $D_{2}$ are strictly positive constants which are to be chosen by the designer such that the polynomial in (8) is Hurwitz polynomial:

$$
p(s)=s^{2}+D_{1} s+D_{2}
$$

Now differentiating (7) with respect to time, we come up with

$$
\begin{aligned}
\dot{s}= & \dddot{e}+D_{1} \ddot{e}+D_{2} \dot{e}, \\
\dot{s}= & \ddot{\omega}(t)+D_{1} \dot{\omega}(t)-\left(\ddot{\theta}_{\text {ref }}(t)+D_{1} \ddot{\theta}_{\text {ref }}(t)\right) \\
& +D_{2}\left(\omega(t)-\dot{\theta}_{\text {ref }}(t)\right) .
\end{aligned}
$$

In order to design control law for FOSMC, we proceed by differentiating (2)

$$
\begin{aligned}
\ddot{\omega} & =\frac{1}{J}\left(\frac{d T_{e}}{d t}-B \frac{d \omega}{d t}-\frac{d T_{L}}{d t}\right), \\
\ddot{\omega} & =\frac{1}{J}\left(\sum_{j=1}^{3} \frac{d T_{j}\left(\theta, i_{j}\right)}{d t}-B \dot{\omega}-\frac{d T_{L}}{d t}\right), \\
\ddot{\omega} & =\frac{1}{J}\left(\sum_{j=1}^{3} \frac{\partial T_{j}\left(\theta, i_{j}\right)}{\partial i_{j}} \frac{d i_{j}}{d t}+\omega \sum_{j=1}^{3} \frac{\partial T_{j}\left(\theta, i_{j}\right)}{\partial \theta}-B \dot{\omega}\right. \\
& \left.-\frac{d T_{L}}{d t}\right) .
\end{aligned}
$$

Substituting (3) into (13) leads to

$$
\begin{aligned}
\ddot{\omega}= & \frac{1}{J}\left(\sum_{j=1}^{3} \frac{\partial T_{j}\left(\theta, i_{j}\right)}{\partial i_{j}}\left(\frac{\partial \lambda_{j}\left(\theta, i_{j}\right)}{\partial i_{j}}\right)^{-1}\right. \\
& \cdot\left(u_{j}-R_{j} i_{j}-\omega \frac{\partial \lambda_{j}\left(\theta, i_{j}\right)}{\partial \theta}\right)+\omega \sum_{j=1}^{3} \frac{\partial T_{j}\left(\theta, i_{j}\right)}{\partial \theta} \\
& \left.-B \dot{\omega}-\frac{d T_{L}}{d t}\right), \\
\ddot{\omega}= & \left.\left.\frac{1}{J}\left(\sum_{j=1}^{3} \frac{\partial T_{j}\left(\theta, i_{j}\right)}{\partial i_{j}}\left(\frac{\partial \lambda_{j}\left(\theta, i_{j}\right)}{\partial i_{j}}\right)^{-1}\right)^{3}\right)_{j}\right) . \\
& \cdot\left(-R_{j} i_{j}-\omega \frac{\partial T_{j}\left(\theta, i_{j}\right)}{\partial \theta}-B \dot{\omega}\right. \\
& +\frac{1}{J}\left(\sum_{j=1} \frac{\left.\partial T_{j}\right)}{d t}\right) \\
& \left(\theta, i_{j}\right) \\
& \left.\left(\frac{\partial \lambda_{j}\left(\theta, i_{j}\right)}{\partial i_{j}}\right)^{-1}\right)
\end{aligned}
$$

This can be written in a compact form as

$$
\ddot{\omega}=F\left(\theta, \omega, i, B, T_{L}\right)+G(\theta, i) u,
$$

where $u$ represents the input vector comprising 3-phase voltages which are being energized at a particular instant to produce net torque and will be determined through the 
commutation scheme described in [32]. The scalar function $F$ and vector function $G$ are defined as

$$
\begin{aligned}
& F\left(\theta, \omega, i, B, T_{L}\right)=\frac{1}{J}\left(\sum_{j=1}^{3} \frac{\partial T_{j}\left(\theta, i_{j}\right)}{\partial i_{j}}\left(\frac{\partial \lambda_{j}\left(\theta, i_{j}\right)}{\partial i_{j}}\right)^{-1}\right. \\
& \cdot\left(-R_{j} i_{j}-\omega \frac{\partial \lambda_{j}\left(\theta, i_{j}\right)}{\partial \theta}\right)+\omega \sum_{j=1}^{3} \frac{\partial T_{j}\left(\theta, i_{j}\right)}{\partial \theta}-B \dot{\omega} \\
& \left.-\frac{d T_{L}}{d t}\right) \\
& G(\theta, i)=\frac{1}{j}\left[\begin{array}{l}
\frac{\partial T_{1}\left(\theta, i_{1}\right)}{\partial i_{1}}\left(\frac{\partial \lambda_{1}\left(\theta, i_{1}\right)}{\partial i_{1}}\right)^{-1} \\
\frac{\partial T_{2}\left(\theta, i_{2}\right)}{\partial i_{2}}\left(\frac{\partial \lambda_{2}\left(\theta, i_{2}\right)}{\partial i_{2}}\right)^{-1} \\
\frac{\partial T_{3}\left(\theta, i_{3}\right)}{\partial i_{3}}\left(\frac{\partial \lambda_{3}\left(\theta, i_{3}\right)}{\partial i_{3}}\right)^{-1}
\end{array}\right]^{-1} .
\end{aligned}
$$

For simplicity, the explicit dependence of $u$ on time $t$ and $F \& G$ vectors on $\theta, \omega, i, B, T_{L}$ will be omitted in the following sections. Therefore,

$$
\ddot{\omega}=F+G u \text {. }
$$

Now (10) can take the form as

$$
\begin{aligned}
\dot{s}= & F+G u+D_{1} \dot{\omega}(t)-\left(\dddot{\theta}_{\text {ref }}(t)+D_{1} \ddot{\theta}_{\text {ref }}(t)\right) \\
& +D_{2}\left(\omega(t)-\dot{\theta}_{\text {ref }}(t)\right) .
\end{aligned}
$$

Proposition 1. The following control law when applied to the motor will stabilize the position to its desired value when $t \rightarrow$ $\infty$ :

$$
u=-G^{-1}\left(F+D_{1} \dot{\omega}(t)+D_{2} \omega(t)+K \operatorname{sign}(s)\right) .
$$

Proof. To prove the convergence, we consider the following candidate Lyapunov function:

$$
V=\frac{1}{2} s^{2},
$$

where $V$ is positive definite.

Differentiating (21) with respect to time, one can get

$$
\dot{V}=s \dot{s} .
$$

For position regulation problem, $\dot{\theta}_{\text {ref }}(t)=\ddot{\theta}_{\text {ref }}(t)=\dddot{\theta}_{\text {ref }}(t)=$ 0 ; then (17) will be modified as

$$
\dot{s}=F+G u+D_{1} \dot{\omega}(t)+D_{2} \omega(t) .
$$

Now combining (22) and (23), we have

$$
\dot{V}=s\left(F+G u+D_{1} \dot{\omega}(t)+D_{2} \omega(t)\right) .
$$

Plugging (20) in (24), we come up with the following equation:

$$
\begin{aligned}
\dot{V} & =s(F \\
& -G G^{-1}\left(F+D_{1} \dot{\omega}(t)+D_{2} \omega(t)+K \operatorname{sign}(s)\right) \\
& \left.+D_{1} \dot{\omega}(t)+D_{2} \omega(t)\right), \\
\dot{V} & =s\left(F-F-D_{1} \dot{\omega}(t)-D_{2} \omega(t)-K \operatorname{sign}(s)\right. \\
& \left.+D_{1} \dot{\omega}(t)+D_{2} \omega(t)\right), \\
\dot{V} & =-K s \operatorname{sign}(s)<0 .
\end{aligned}
$$

Now it is clear from (27) that $\dot{V}=0$ only when $s=0$, so we can see that

(1) $V$ is positive definite,

(2) $\dot{V}$ is negative definite.

Therefore, we conclude that the control law as defined in (20) would guarantee that $\theta(t) \rightarrow \theta_{\text {ref }}(t)$ when $t \rightarrow \infty$.

3.2. Second-Order Sliding Mode Controller (SOSMC) Design. The higher-order sliding-mode (HOSM) is basically the extension of conventional sliding mode acting on the higherorder derivatives of the sliding variable. HOSM has the ability to remove the chattering effect completely and provides higher accuracy in realization while maintaining the basic advantage of original approach. Several numbers of such controllers have been reported in the literature [34-36]. Among these, the second-order sliding mode controller (SOSMC) is popular due to its easy implementation.

The sliding order defines the dynamics smoothness degree in the vicinity of the sliding mode. Simply, sliding order is the number of total continuous time derivatives of the sliding variable. Therefore, conventional sliding mode is synthesized with sliding order one, whereas SOSMC is formulated on the second time derivative of the sliding order and so on. To design SOSMC, a number of algorithms have been introduced in the literature in which twisting, super twisting, suboptimal, and drift are common. The super twisting algorithm has the advantage over other algorithms in that it does not require the time derivatives of sliding variable. Moreover, it is not sensitive to sampling time and guarantees the system trajectories twisting around the origin in the phase portrait and converges to it in finite time. This algorithm has been successfully applied on various areas including engineering and nonengineering applications [36-38]. In this algorithm, the control law is composed of two terms: the one term $u_{a}$ is expressed in terms of discontinuous time derivative 


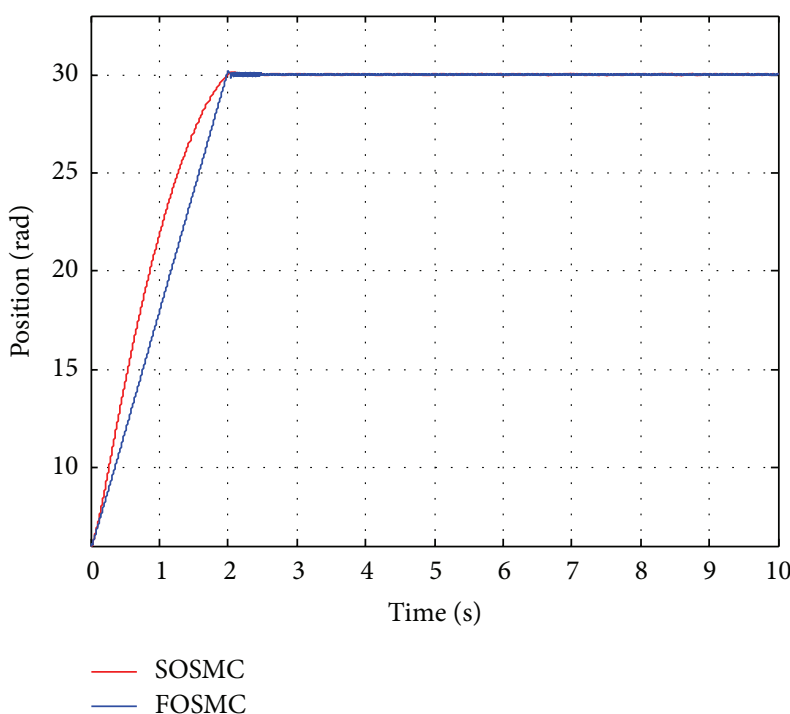

FIGURE 1: Position response of FOSMC and SOSMC to a step command.

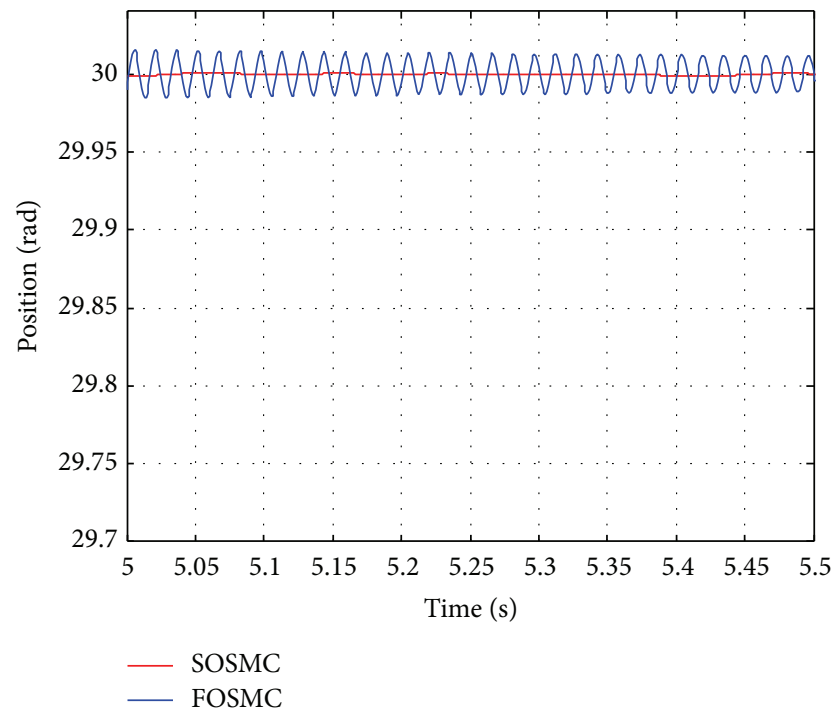

FIGURE 2: A close-up view of responses of both FOSMC and SOSMC to a step command. The high magnitude of chattering signal of FOSMC is clearly noticeable.

and the second term $u_{b}$ is a continuous function of sliding variable $[39,40]$ :

$$
\begin{aligned}
& u=u_{a}+u_{b}, \\
& \dot{u}_{a}=\left\{\begin{array}{l}
-u, \\
-K \operatorname{sign}(s), \quad \text { when }|u|>1,
\end{array}\right. \\
& u_{b}=\left\{\begin{array}{l}
-\lambda\left|s_{0}\right|^{\xi} \operatorname{sign}(s) \text { when }|s|>s_{0} \\
-\lambda|s|^{\xi} \operatorname{sign}(s) \quad \text { when }|s| \leq s_{0} .
\end{array}\right.
\end{aligned}
$$

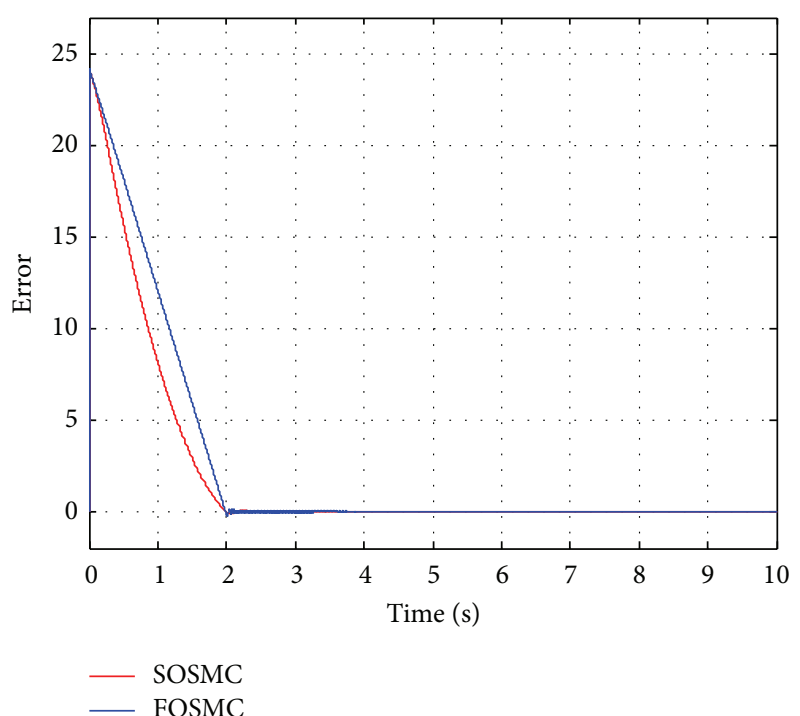

FIGURE 3: Error plot of position responses of FOSMC and SOSMC to a step command.

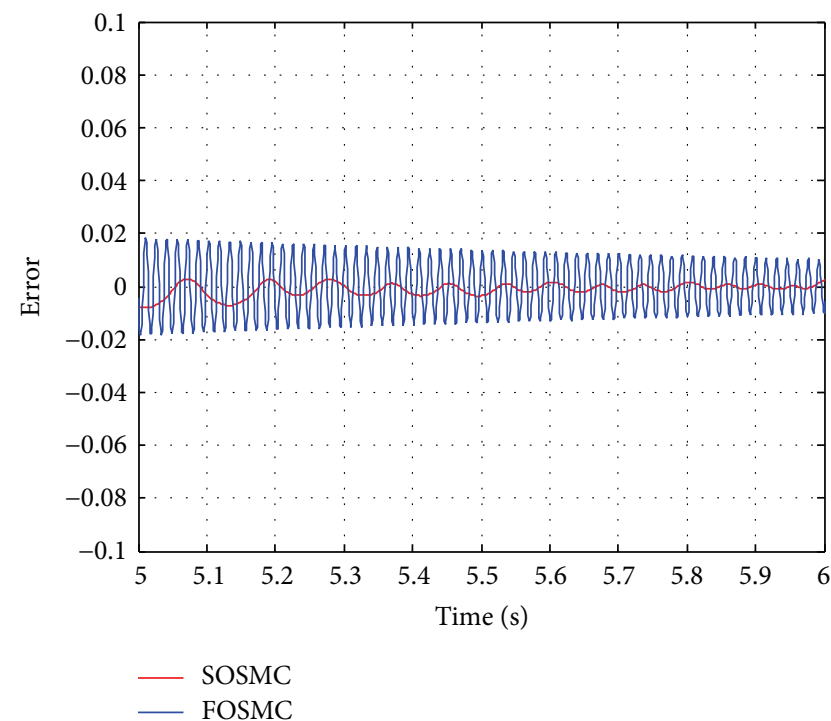

FIGURE 4: A close-up view of error plot of position responses for FOSMC and SOSMC to a step command in initial stage of steady state.

The super twisting algorithm converges in finite time and the corresponding sufficient conditions are

$$
\begin{aligned}
& K>\frac{\Phi}{\Gamma_{m}}, \\
& \lambda^{2} \geq \frac{4 \Phi}{\Gamma_{m}^{2}} \frac{\Gamma_{m}(K+\Phi)}{\Gamma_{m}(K-\Phi)}, \\
& 0<\xi \leq 0.5,
\end{aligned}
$$



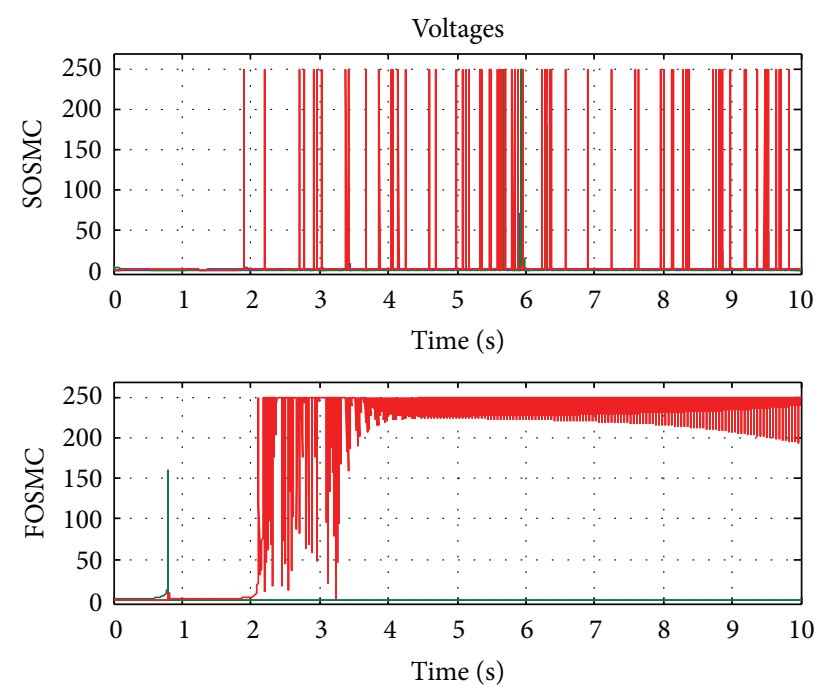

Figure 5: Phase voltages during simulated period for a simulation run of 10 seconds.
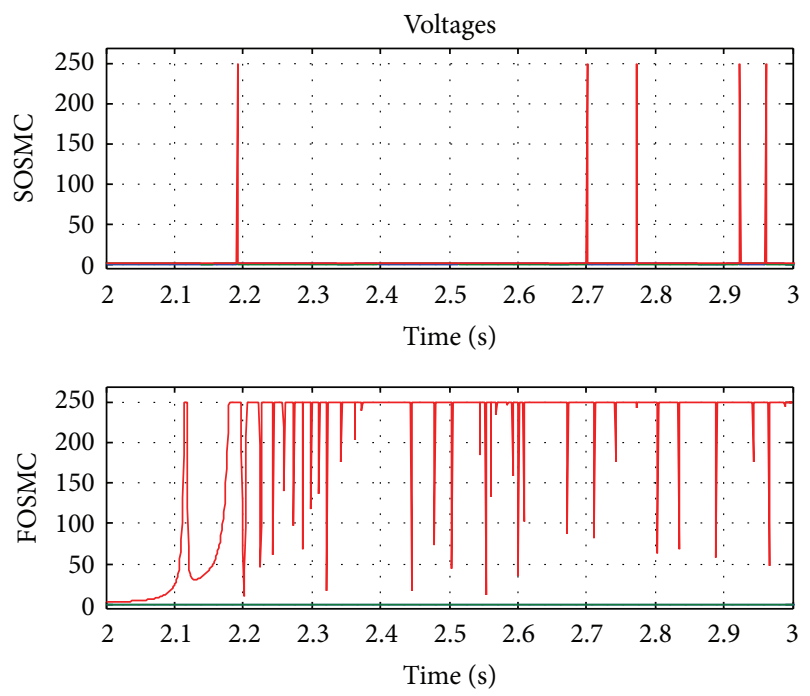

FIGURE 6: Phase voltages during transient response.

where $K, \lambda, s_{0}, \Phi, \Gamma_{m}$ are some positive constants. When controlled system is linearly dependent on $u$, the control law can be simplified as

$$
\begin{aligned}
u & =-\lambda|s|^{\xi} \operatorname{sign}(s)+u_{a}, \\
\dot{u}_{a} & =-K \operatorname{sign}(s) .
\end{aligned}
$$

When $\xi=1$ then this algorithm converges to the origin exponentially.

Finally, the control law in SOSMC takes the following form for position regulation problem:

$$
\begin{aligned}
u= & -G^{-1}\left(F+\lambda_{1} \dot{\omega}(t)+\lambda_{2} \omega(t)+\lambda|s|^{0.5} \operatorname{sign}(s)\right) \\
& +u_{a}, \\
\dot{u}_{a}= & -K \operatorname{sign}(s) .
\end{aligned}
$$

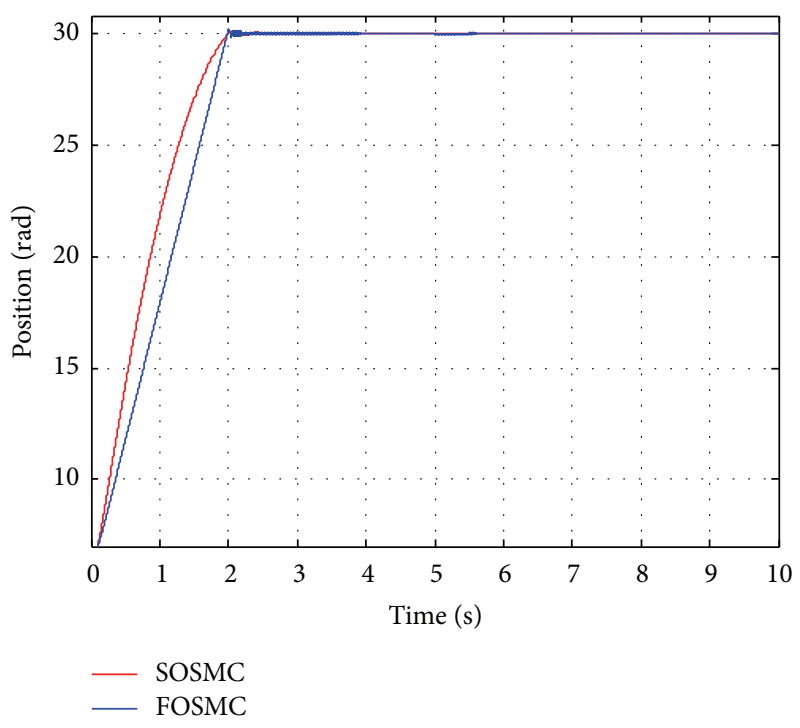

FIGURE 7: Position response of controllers with sudden torque load.

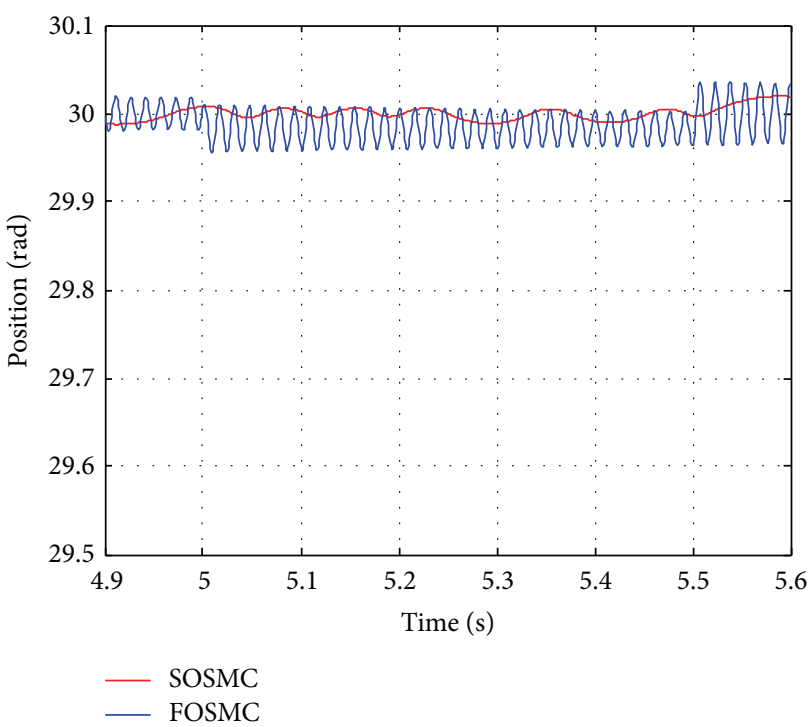

FIGURE 8: A close-up view of position response of controllers with sudden torque load.

\section{Results and Discussions}

SR motor described in Section 2 along with sliding mode controllers is simulated using MATLAB/SIMULINK software. The reference position is set to 30 radian. From the results shown in Figures 1-4, it can be noticed that motor position converges to the desired position within 2 seconds. Figure 3 shows the respective error plot and Figure 4 gives its closeup view. This is important to see that chattering is observed in FOSMC as is indicated by Figures 2 and 4 . The input voltages of SR motor phases as controlled by FOSMC and SOSMC are plotted in Figures 5 and 6. It can be observed from these figures that SOSMC saves the power consumption as the phase voltages values in SOSMC are low being less in area under the curve. 


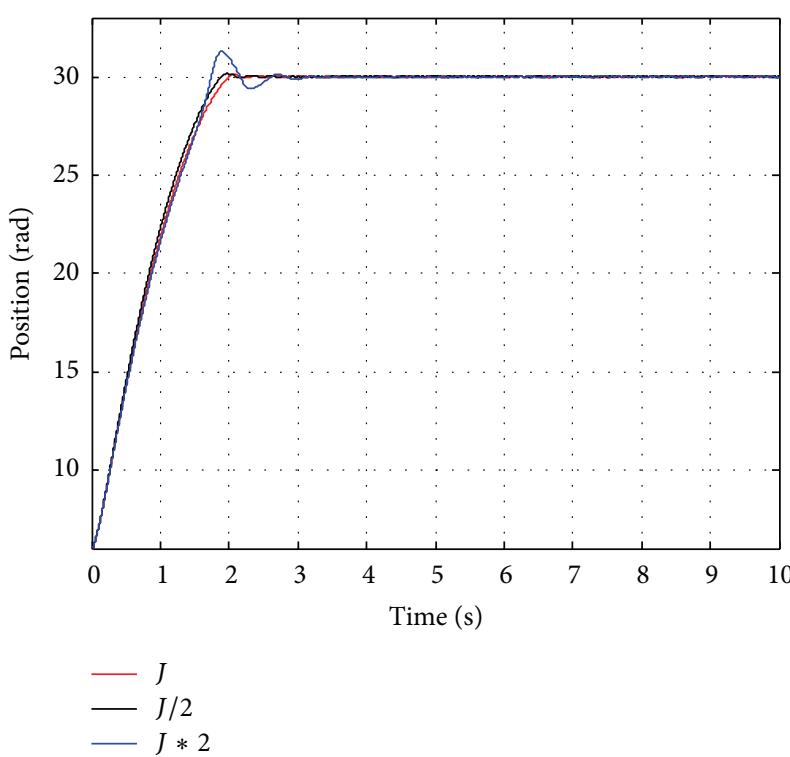

Figure 9: Position response of proposed design with changes in $J$.

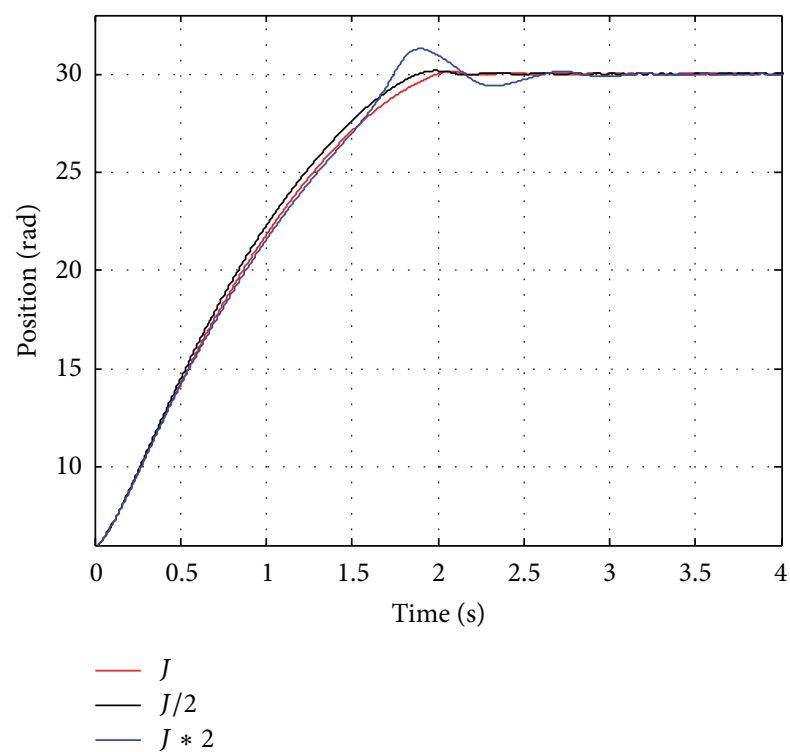

FIgURE 10: A close-up view of Figure 9 with changes in $J$.

A good performance of SOSMC can be observed from Figures 7 and 8 when SR motor experiences a sudden change in torque load from 0 to $2 \mathrm{~N} \cdot \mathrm{m}$ at $t=5$ seconds until $t=5.5$ second where sudden change is removed.

Both the controllers are put to test for the same change. The performance of both the controllers is not observed clearly from Figure 7; therefore, its close-up view is plotted in Figure 8. It can be seen that FOSMC is producing more chattering than SOSMC. It is important to note that high frequency and higher magnitude of chattering is dangerous when an actuator has to obey such a control command. Therefore, the SOSMC is a better choice for controller and is producing better overall results for SR motor control.

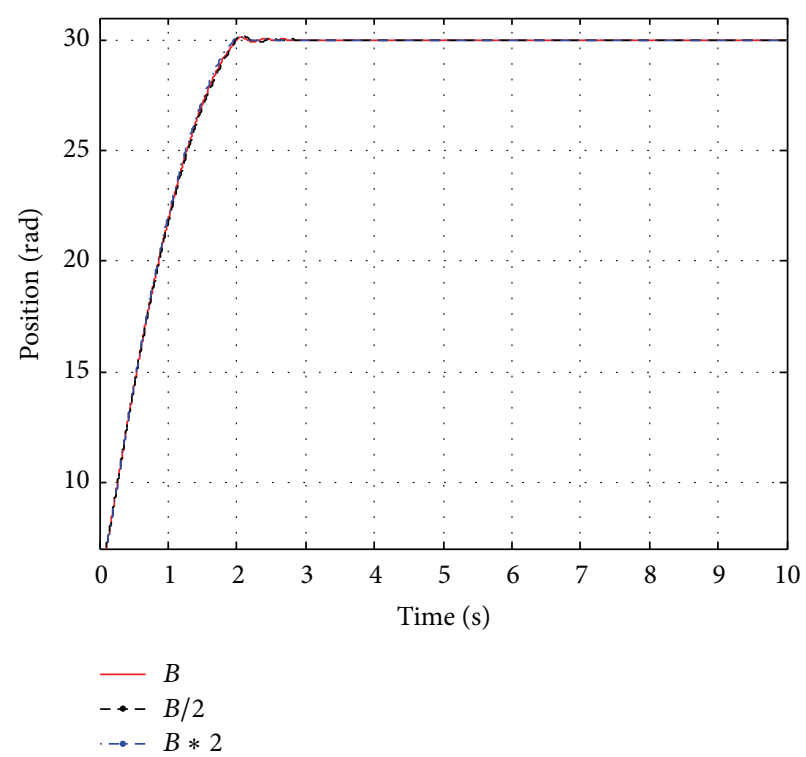

FIGURE 11: Position response of proposed design with changes in $B$.

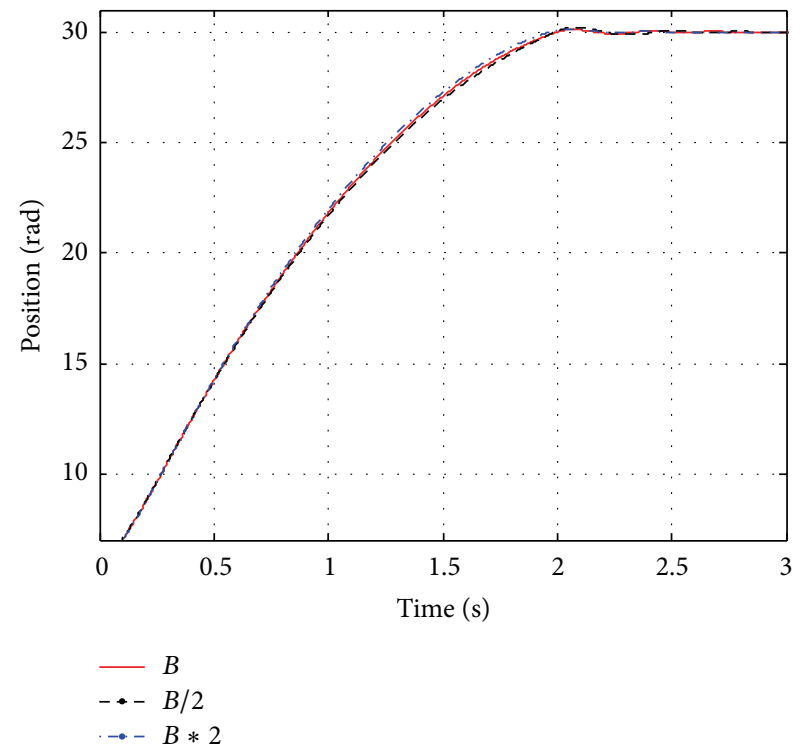

Figure 12: A close-up view of Figure 11 with changes in $B$.

To further investigate the performance of the proposed controller SOSMC, a test of parameters variations is carried out. In this experiment, the value of one parameter is changed at one time while keeping the other parameters unchanged. The motor is commanded to attain a position 30 radian under no torque load. Figure 9 shows the motor response when moment of inertia is first decreased by $50 \%$ and then increased by $100 \%$ from its original value. The decrease in moment of inertia improves the dynamic response of the motor but increase of moment of inertia causes some overshoot in the transient stage as it is clearly indicated in Figure 10.

Figure 11 shows the motor response when the same changes in coefficient of friction are taken. The decrease 


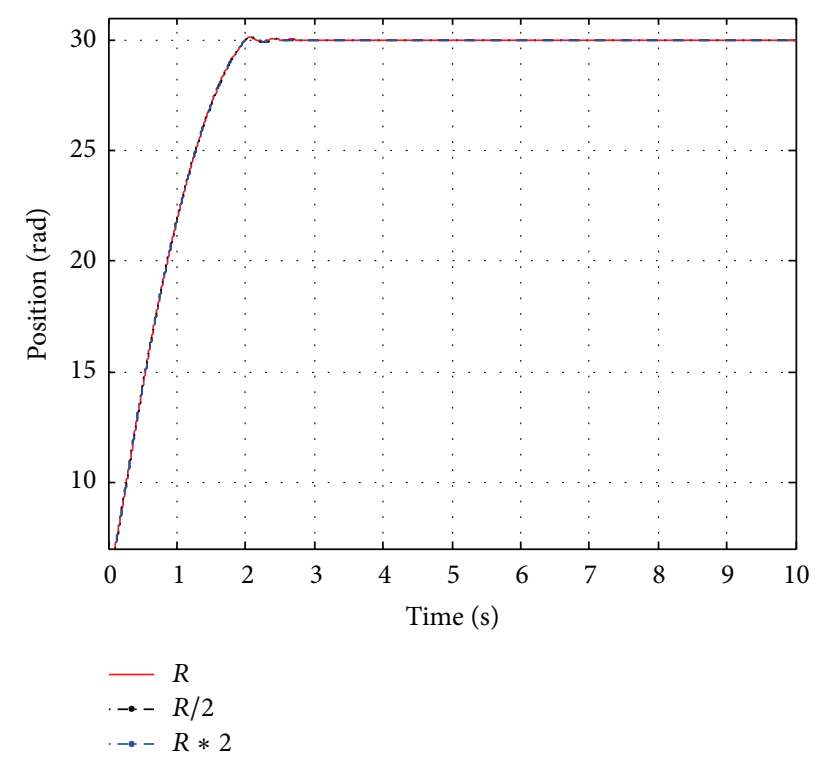

FIgURE 13: Position response of proposed design with changes in $R$.

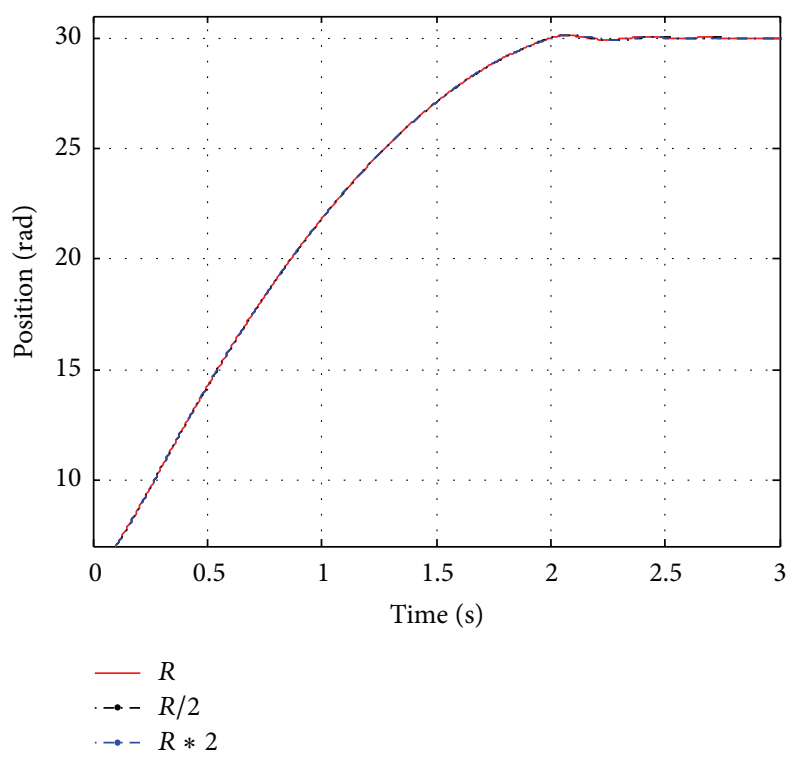

Figure 14: A close-up view of Figure 13 with changes in $R$.

in coefficient of friction does not impose any effect on the dynamic response whereas the increase in coefficient of friction improves the dynamic response as shown in Figure 12.

Figure 13 shows the response when changes in coefficient of resistance are made. It is clear from Figure 14 that the increment or decrement of coefficient of resistance does not pay any effect on the dynamic response. Hence, by the above discussion, it is evident that the proposed controller is robust to parameter variations and unknown disturbances.

\section{Conclusions}

In this paper the position regulation problem of SR motor has been discussed and SOSMC, based on super twisting algorithm, is proposed for chattering reduction inherent in FOSMC. The proposed controller is robust against parameter variations and unknown disturbances.

\section{Conflict of Interests}

The authors declare that there is no conflict of interests regarding the publication of this paper.

\section{References}

[1] R. Krishnan, Switched Reluctance Motor Drives: Modeling, Simulation, Analysis, Design, and Applications, CRC Press, Boca Raton, Fla, USA, 2001.

[2] Y. Xu, H. Chen, and J. Gu, "Power loss analysis for switched reluctance motor converter by using electrothermal model," IET Power Electronics, vol. 8, no. 1, pp. 130-141, 2015.

[3] S. Rafael, P. J. C. Branco, and A. J. Pires, "Position control of an 8/6 switched reluctance machine without current sensor," in Proceedings of the 2nd International Conference on Power Engineering, Energy and Electrical Drives (POWERENG '09), pp. 327-330, IEEE, Lisbon, Portugal, March 2009.

[4] M. D. Leviner, D. M. Dawson, and J. Hu, "Position tracking control of a switched reluctance motor using partial state feedback," in Proceedings of the American Control Conference, pp. 3095-3099, IEEE, July 1994.

[5] W.-S. Baik, M.-H. Kim, D.-H. Kim, K.-H. Choi, and D.H. Hwang, "A high performance motion control system of switched reluctance motor," in Proceedings of the 37th IEEE Power Electronics Specialists Conference (PESC '06), pp. 1-5, IEEE, Jeju, The Republic of Korea, June 2006.

[6] W.-C. Gan, N. C. Cheung, and L. Qiu, "Position control of linear switched reluctance motors for high-precision applications," IEEE Transactions on Industry Applications, vol. 39, no. 5, pp. 1350-1362, 2003.

[7] G.-Z. Cao, L.-M. Lin, H. Qiu, and J. F. Pan, "Design and analysis of a dSPACE-based position control system for a linear switched reluctance motor," in Proceedings of the 3rd International Conference on Power Electronics Systems and Applications (PESA '09), pp. 1-4, Hong Kong, May 2009.

[8] J. Zhang and A. V. Radun, "A new method to measure the switched reluctance motor's flux," IEEE Transactions on Industry Applications, vol. 42, no. 5, pp. 1171-1176, 2006.

[9] S. Song, L. Ge, S. Ma, M. Zhang, and L. Wang, "Accurate measurement and detailed evaluation of static electromagnetic characteristics of switched reluctance machines," IEEE Transactions on Instrumentation and Measurement, vol. 64, no. 3, pp. 704-714, 2015.

[10] V. I. Utkin and H.-C. Chang, "Sliding mode control on electromechanical systems," Mathematical Problems in Engineering, vol. 8, no. 4-5, pp. 451-473, 2002.

[11] Y. Xu, H. Chen, and J. Gu, "Power loss analysis for switched reluctance motor converter by using electrothermal model," IET Power Electronics, vol. 8, no. 1, pp. 130-141, 2014.

[12] J. W. Cheon, S. B. Choi, H. J. Song, and J. H. Ham, "Position control of an AC servo motor using sliding mode controller with disturbance estimator," International Journal of Precision Engineering and Manufacturing, vol. 5, no. 4, pp. 14-20, 2004. 
[13] J. De Leon-Morales, R. Castro-Linares, and O. H. Guevara, "Observer-based controller for position regulation of stepping motor," IEE Proceedings-Control Theory and Applications, vol. 152, no. 4, pp. 465-476, 2005.

[14] A. Susperregui, G. Tapia, and A. Tapia, "Application of two alternative sliding-mode control approaches to DC servomotor position tracking," IET Electric Power Applications, vol. 1, no. 4, pp. 611-621, 2007.

[15] H. Hashimoto, H. Yamamoto, S. Yanagisawa, and F. Harashima, "Brushless servo motor control using variable structure approach," IEEE Transactions on Industry Applications, vol. 24, no. 1, pp. 160-170, 1988.

[16] A. Levant, Higher order sliding modes and their application for controlling uncertain processes [Ph.D. dissertation], Institute for System Studies of the USSR Academy of Science, Moscow, Russia, 1987.

[17] M. K. Gupta, A. K. Sharma, and D. Patidar, "A robust variable structure position control of DC motor," Journal of Theoretical and Applied Information Technology, vol. 4, no. 10, 2008.

[18] R. Pupadubsin, N. Chayopitak, N. Nulek et al., "An improved adaptive sliding mode position control of a linear variable reluctance motor," in Proceedings of the International Conference on Electrical Machines and Systems (ICEMS '10), pp. 1583-1588, Incheon, South Korea, October 2010.

[19] M. Abid, A. Mansouri, A. G. Aissaoui, and B. Belabbes, "Sliding mode application in positoin control of an induction machine," Journal of Electrical Engineering, vol. 59, no. 6, pp. 322-327, 2008.

[20] A. G. Aissaoui, M. Abid, H. Abid, and A. Tahour, "Position control of synchronous machine using sliding mode techniques," Journal of Electrical \& Electronics Engineering, vol. 7, no. 2, pp. 471-480, 2007.

[21] P. Phongsak, "Robust position control of an induction motor using a fuzzy logic sliding mode model following controller (FLSMFC) with sinusoidal command input," Journal of Research in Engineering and Technology, vol. 6, pp. 361-377, 2009.

[22] A. E. Bakly, A. Fouda, and W. Sabry, "A proposed DC motor sliding mode position controller design using fuzzy logic and PID techniques," in Proceedings of the 13th International Conference on Aerospace Sciences \& Aviation Technology (ASAT '09), Cairo, Egypt, May 2009.

[23] T. C. Chen and J. U. Hsu, "A fuzzy sliding mode controller for induction motor position control," in Proceedings of the IEEE 20th International Conference on Industrial Electronics, Control and Instrumentation (IECON '94), vol. 1, pp. 44-49, Bologna, Italy, September 1994.

[24] M. Fallahi and S. Azadi, "Fuzzy PID sliding mode controller design for the position control of a DC motor," in Proceedings of the International Conference on Education Technology and Computer (ICETC '09), pp. 73-77, IEEE, Singapore, April 2009.

[25] M. H. Zadeh, A. Yazdian, and M. Mohamadian, "Robust position control in DC motor by fuzzy sliding mode control," in Proceedings of the International Symposium on Power Electronics, Electrical Drives, Automation and Motion (SPEEDAM '06), pp. 1413-1418, Taormina, Italy, May 2006.

[26] Q. R. Butt and A. I. Bhatti, "Estimation of gasoline-engine parameters using higher order sliding mode," IEEE Transactions on Industrial Electronics, vol. 55, no. 11, pp. 3891-3898, 2008.

[27] Q. R. Butt, A. I. Bhatti, M. R. Mufti, M. A. Rizvi, and I. Awan, "Modeling and online parameter estimation of intake manifold in gasoline engines using sliding mode observer," Simulation Modelling Practice and Theory, vol. 32, pp. 138-154, 2013.
[28] M. Rafiq, S.-U. Rehman, F.-U. Rehman, Q. R. Butt, and I. Awan, "A second order sliding mode control design of a switched reluctance motor using super twisting algorithm," Simulation Modelling Practice and Theory, vol. 25, pp. 106-117, 2012.

[29] Q. R. Butt, A. I. Bhatti, M. Iqbal, M. A. Rizwi, R. Mufti, and I. H. Kazmi, "Estimation of automotive engine parameters. Part I. Discharge coefficient of throttle body," in Proceedings of the 6th International Bhurban Conference on Applied Sciences and Technology (IBCAST '09), pp. 275-280, IEEE, Islamabad, Pakistan, January 2009.

[30] K. B. Gob, M. W. Dunnigan, and B. W. Williams, "Robust chattering-free (higher order) sliding mode control for a vectorcontrolled induction machine," in Proceedings of the 5th Asian Control Conference, vol. 2, pp. 1362-1370, Melbourne, Australia, July 2004.

[31] M. Rafiq, S.-U. Rehman, F.-U. Rehman, and Q. R. Butt, "Performance comparison of PI and sliding mode for speed control applications of SR motor," European Journal of Scientific Research, vol. 50, no. 3, pp. 368-384, 2011.

[32] M. Rafiq, S. U. Rehman, Q. R. Butt, and A. I. Bhatti, "Power efficient sliding mode control of SR motor for speed control applications," in Proceedings of the 13th International Multitopic Conference (INMIC '09), pp. 1-6, IEEE, Islamabad, Pakistan, December 2009.

[33] J. J. E. Slotine and L. Weiping, Applied Nonlinear Control, Prentice Hall, Englewood Cliffs, NJ, USA, 1991.

[34] A. Farhoud and A. Erfanian, "Fully automatic control of paraplegic FES pedaling using higher-order sliding mode and fuzzy logic control," IEEE Transactions on Neural Systems and Rehabilitation Engineering, vol. 22, no. 3, pp. 533-542, 2014.

[35] S. Laghrouche, M. Harmouche, F. S. Ahmed, and Y. Chitour, "Control of PEMFC air-feed system using lyapunov-based robust and adaptive higher order sliding mode control," IEEE Transactions on Control Systems Technology, vol. 23, no. 4, pp. 1594-1601, 2015.

[36] M. Cucuzzella, G. P. Incremona, and A. Ferrara, "Design of robust higher order sliding mode control for microgrids," IEEE Journal on Emerging and Selected Topics in Circuits and Systems, vol. 5, no. 3, pp. 393-401, 2015.

[37] C. Evangelista, P. Puleston, F. Valenciaga, and L. M. Fridman, "Lyapunov-designed super-twisting sliding mode control for wind energy conversion optimization," IEEE Transactions on Industrial Electronics, vol. 60, no. 2, pp. 538-545, 2013.

[38] J. J. Rath, K. C. Veluvolu, and M. Defoort, "Simultaneous estimation of road profile and tire road friction for automotive vehicle," IEEE Transactions on Vehicular Technology, vol. 64, no. 10, pp. 4461-4471, 2015.

[39] G. Eder and A. M. Jaime, "Super-twisting observer for secondorder systems with time-varying coefficient," IET Control Theory and Applications, vol. 9, no. 4, pp. 553-562, 2015.

[40] M. K. Khan, K. B. Goh, and S. K. Spurgeon, "Second order sliding mode control of a diesel engine," Asian Journal of Control, vol. 5, no. 4, pp. 614-619, 2003. 


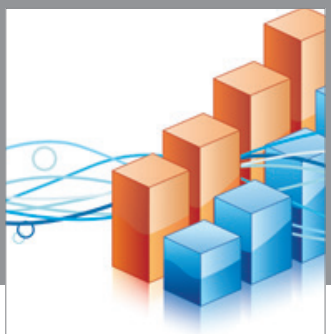

Advances in

Operations Research

vatem alat4

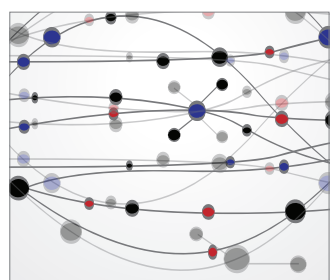

\section{The Scientific} World Journal
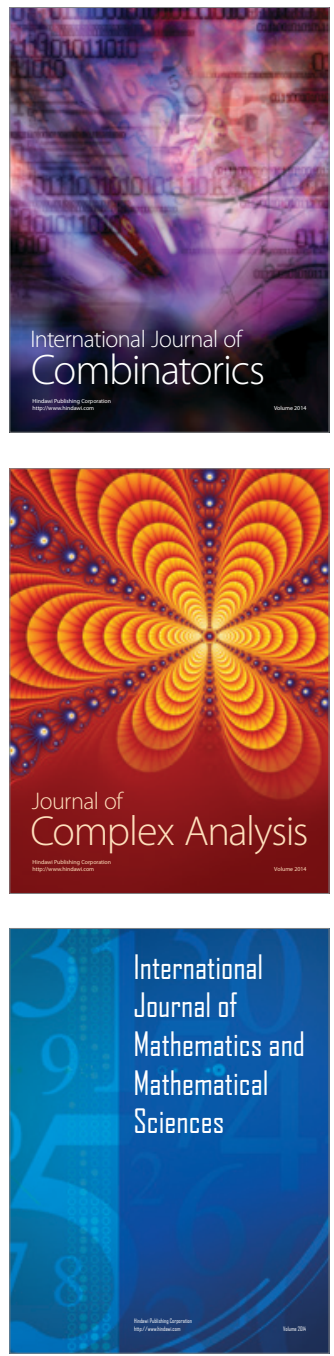
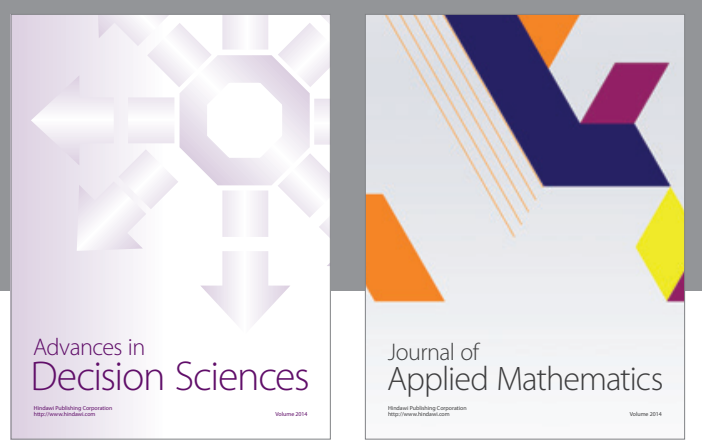

Algebra

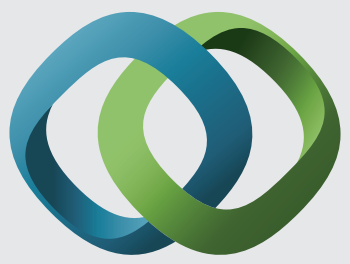

\section{Hindawi}

Submit your manuscripts at

http://www.hindawi.com
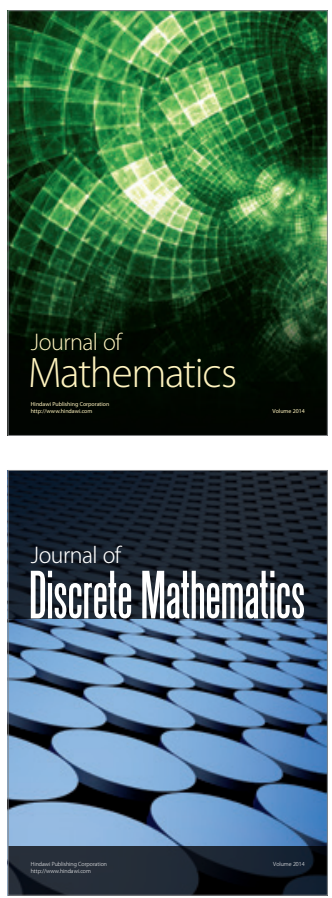

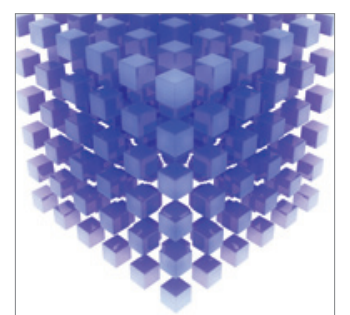

Mathematical Problems in Engineering
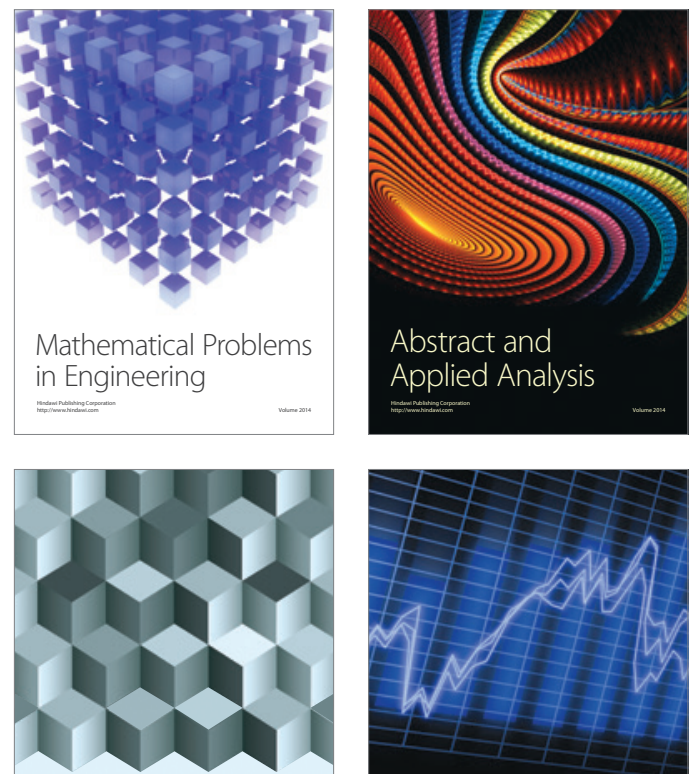

Journal of

Function Spaces

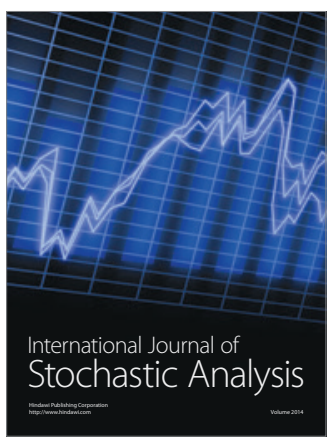

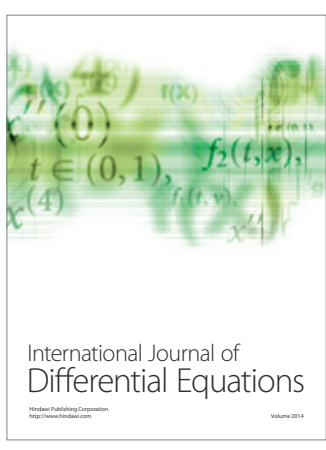
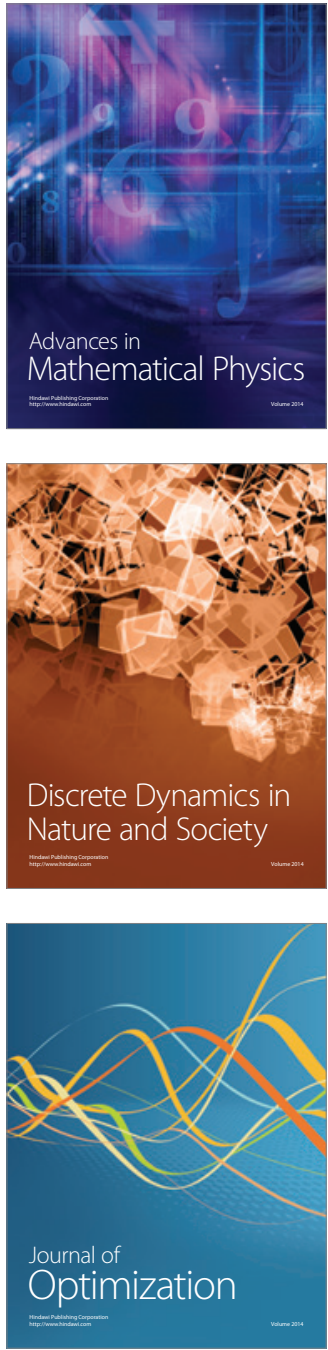